\title{
ELECTROMAGNETIC DISTANCE MEASUREMENT
}

\begin{abstract}
CHE International Association of Geodesy, on the invitation of the Royal Society of London, held a symposium on "Electromagnetic Distance Measurement" at Oxford during September 6-10, 1965. The precise measurement of long distances on the Earth's surface, and also to artificial satellites, has become an increasingly important technique of geodesy during the past twenty years. Numerous instruments are now available commercially for this purpose, using either modulated light or microwave beams, and much research is going on, including work on the application of lasers to distance measurement.

These instruments have created new problems for geodesists who seek accuracies of ono or two parts per million. The speed of light is a vital parameter in the calculations, and the effect of atmospheric refraction is most important. The precise determination of the mean refractive index for long lines through the atmosphere at present constitutes the most intractable problem. A further complication with microwaves is that they are reflected from surfaces below or adjacent to the line measured, causing difficulties in observation and uncertainties in the final determination.
\end{abstract}

It was to investigate these and other associated problems, and to evaluate the available instruments, that Special Study Group No. 19 of the International Association of Geodesy was formed in 1958. The symposium was convened by Major-General R. C. A. Edge, president of the Study Group (and now director-general of the Ordnance Survey), to provide a forum in which the geodesists' problems could be discussed with physicists and meteorologists from all over the world whose work had an important bearing on the subject.

The working sessions covered microwave instruments. electro-optical instruments, propagation problems, laser applications, airborne systems, ranging to artificial Earth satellites, and finally the precise measurement of distances of the order of $1 \mathrm{~km}$ or less to accuracies better than one part per million. This last is a newcomer to the work of the Study Group, but one of increasing importance in precise engineering, as for example in the construction of particle accelerators. Plans are now being made to publish a full record of the proceodings, including discussions.

Further information concerning the symposium may be obtained from the Director-General of the Ordnance Survey, Leatherhead Road, Chessington, Surrey.

\section{AUSTRALIAN BIOCHEMICAL SOCIETY MEETING}

\begin{abstract}
A MEETING of the Australian Biochemical Society was held at Monash University, Clayton, Victoria, during August 24-27. It took the form of general research papers and symposia on protein structure, function and synthesis-the latter in relation to the genetic apparatus-and the genesis and function of membrane systems. Speakers from overseas and Australia were invited.
\end{abstract}

S. Moore discussed the chemistry of the catalytic site of ribonuclease with particular reference to the histidine residues at positions 12 and 119 and the lysine residue at position 41. The proportion of each histidine alkylated at nitrogen- 1 of histidine 119 and at nitrogen-3 of histidine 12 was found to vary with the chain-length and the particular isomer of the alkylating agent. Charged substitution (carboxymethyl) of lysine-41 lowered the rate of histidine alkylation, but an uncharged (carboxyamido) derivative did not affect it. The spatial relationships of these three amino-acid side-chains as a part of the active centre can now be visualized.

The mechanism of action of certain hydrolytic enzymes as followed by kinetic analysis of the formation of acyl intermediates and their subsequent rate of decey was discussed by $\mathrm{B}$. Zerner. In the case of chymotrypsin and trypsin the decay of the acyl derivative was found to be the rate-limiting step. The mechanism of hydrolysis by liver carboxylesterases, ureaso and cortain other proteolytic enzymes seems to follow the sæme general chemistry of an acyl enzyme intermediate. He pointed out that the detailed chemistry underlying enzyme spocificity is still unsolved.

E. O. P. Thompson gave an account of the accumulated information concerning keratin structure with particular emphasis on Australia's national product, wool. Urea and a reducing agent are required to disrupt the firmly bound structure. Subsequent alkylation of the thiol groups so formed gives protein fractions amenable to conventional separation mothods. The large number of acetyl end groups is of considerable interest. Three general hetero geneous classes of protein are present in wool-high sulphur, low sulphur and high glyeine. The high sulphur proteins are found in the matrix between the fibrillar structures and may vary from 22 to 31 per cent with forced feeding. Serious attention is now being given to the bottom (growing) end of the wool fibres. There are suggestions that the high sulphur proteins are former later than the rest and that consolidation of the protein system occurs higher up the fibre.

What was true and new about our oldest and best known protein system-gluten-was amusingly discussed by M. V. Tracey. In latter years the separation methods successfully applied to other protein systems have been tested and shown to be not very useful with gluten. But the attempts have gone on. The protein as it occurs in flour has the original characteristics of the protein as synthesized, but with maturation of the grain, etc., subsequent alterations have been superimposed. Mr. Tracey. in opposition to the simplifiers, pointed out that, as isolated from the flour, the gluten complex has a range of molecular weights of 20,000 to many millions. Using commonsense arguments he pointed out that random polymeriza.tion through disulphide cross-linking would give rise to giant molocules. He argued further that an allo-polyploid with endosperm cells having throe sets of chromosomes plus accumulated mutations would not be expected to synthesize storage proteins of simple variety.

V. Moses discussed the observation that proteins synthesized in $E$. coli, after depleted cells have bcen supplied with nutrients, appear at different rates. This discrimination was interpreted in terms of stability differences in the related molecules of $m \mathrm{RNA}$. Ho rsised the question of the control of protein synthesis when the related $m \mathrm{RNA}$ is of the stable kind. If it is exercised. eontrol in such a situation must be at a later stage than transcription of DNA. B. W. Holloway reviewed the evidence relating to a general operon hypothesis for control 